\title{
A Three-Tier Salary Management System for Higher Vocational Colleges
}

\author{
Bin Lu ${ }^{1}$, Changyu Liu ${ }^{2,3, *}$ and Tiezhu Zhao ${ }^{4}$ \\ ${ }^{1}$ School of Computer Science, Wuyi University, Jiangmen 529020, China \\ ${ }^{2}$ School of Computer Science and Engineering, South China University of \\ Technology, Guangzhou 510006, China \\ ${ }^{3}$ Department of Electrical and Computer Engineering, University of Miami, Coral \\ Gables, FL 33146, USA \\ ${ }^{4}$ Computer College, Dongguan University of Technology, Dongguan 523808, \\ China \\ lbscut@gmail.com, *yezhich@gmail.com (corresponding author), \\ tzzhao83@163.com
}

\begin{abstract}
In this paper, we design and implement a three-tier salary management system for higher vocational colleges. At the beginning, we conduct an overview of the entire present situation of the salary management mechanism for the higher vocational colleges, and propose to improve the financial work efficiency of the higher vocational colleges by using ASP.NET based information management system. Then, we analyze the primary system requirements and divide the system into four functional modules, which are the salary management module, the system management module, the login module, and the query as well as report module. Next, for the system design, we present details about the use case design, the data process design, the business process design, the database design, and the design of architecture as well as modules. Last, we implement the system based on a three-tier architecture, which are the user presentation tier, the business logic tier and the data access tier.
\end{abstract}

Keywords: three-tier architecture, salary management system, higher vocational colleges

\section{Introduction}

With the development of science and technology, information systems play a more and more important role in our daily lives. The ability to introduce effectively these information systems into daily managements is crucial to both the operation and the development of one department or one organization. As one kind of information systems, the salary management system has become one of the most important components for higher vocational colleges. Traditionally, several financial staffs are required to manage manually a huge number of payroll records. The substitution of information systems for financial staffs in the salary management could bring many advantages, such as an efficient output of the salary report and an accurate payroll accounting, requesting eagerly efficient salary management systems.

At present, the salary mechanism, which mixes the state salary and the campus subsidy into the final payroll record, is carried out extensively by most of higher vocational colleges in China. Research reported that the mechanism has several severe defects, which are the serious equalitarianism liability in income allocation, the tendency of economic rewards and low levels of income. Besides, although there are various salary management systems available in the Chinese market, such as TalentBaseTM, UFSOFT HR, 
YKHRMIS and K3eHR, they are not designed originally and suitable for higher vocational colleges.

Therefore, a more effective salary management is imperative for higher vocational colleges. In this paper, we developed an asp.net based salary management system for higher vocational colleges. The system is based three-tier $\mathrm{B} / \mathrm{S}$ architecture and four functional modules. We also illustrate our system from three aspects, which are the requirement analysis, the system design and the system implementation.

\section{Requirement Analysis}

As first step the software lifecycle, the requirement analysis could bridge the gap between project problems and their solutions to establish proper models. In software engineering, the requirement analysis involves those tasks that analyze the needs for a new product, consider possibly conflicting requirements from various stakeholders, document, validate and manage system requirements [1]. Functional requirement, one of the most important parts of the requirement analysis, defines necessary functions of a system to meet requirements of system users, which are described as a set of inputs, behaviors and outputs.

The primary functions of the required salary management system are to support convenient maintenances of payroll records of the faculty and effective reductions of the management cost. Accordingly, we divide the required salary management system into four functional modules, which are the salary management module, the system management module, the login module, and the query as well as report module, as follows.

(1) The salary management module. The financial department could use this module to maintain conveniently payroll records of the faculty, from five aspects, which are basic settings, payroll input, payroll audit, payment of salaries, and treatment at the end of a month. For basic settings, this module should provide functions of parameters modification, such as the income tax rate, and items modification, such as public reserve funds in gross wages, to the financial department, in the calculation formula of wages. For payroll input, this module should offer functions of Excel files uploading, batch operations, and manual inputs to the financial department. For payroll audit and payment of salaries, this module should supply specific users with corresponding operating permissions. For treatment at the end of a month, this module should consider how to conduct efficient and effective financial statements.

(2) The system management module. This module should provide its main users, which are the system administrators and the personnel department, with permission management, archive management and database management. For the permission management, the functional requirements include role management, permission assignment and permission adjustment. For the archive management, the system should provide users with an easy maintenance of basic information, title information and salary information for the faculty. For the database management, both the database backup and the database restore are required.

(3) The login module. Major functions of this module are selecting of access control methods, such as the role based access control (RBAC), considering whether adopt the IP login restrictions, identifying the verification code, and exiting the system dynamically. For example, if there is no response from the logged user over five minutes, the user logouts automatically from the current session.

(4) The query and report module. Four functions, which are queries under configurable conditions, queries of payment records, queries of users and printing management, are achieved in the system. For queries under configurable conditions, the system is required to provide users with single key word based queries, multiple key words based queries and fuzzy queries. For queries of payment records, the system is required to provide users 
with queries of payroll records and queries of aggregate payment records. For queries of users, the system provides both employee number based and department based queries. For printing managements, we would like to obtain the following services, which are setting of printer, printing of payroll records, and printing of user information.

\section{System Design}

\subsection{Architecture and Modules}

Architecture design is needed once we complete the requirement analysis. In this paper, we combine C\#, Asp.net, SQL Server and IIS in .NET based three-tier B/S architecture, which are the user presentation tier, the business logic tier, and the data access tier, where upper tiers rely on lower tiers, as shown in Figure 1.

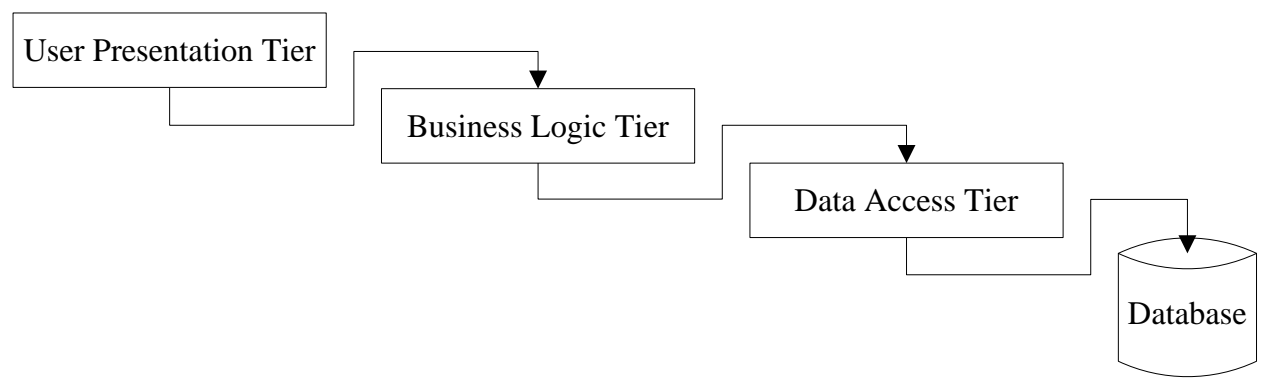

Figure 1. Three-tier B/S Architecture

We can then proceed to design function modules once we choose the appropriate architecture. According to the requirement analysis, our system consists of four major functional modules, which are the salary management module, the system management module, the login module, and the query as well as report module. Furthermore, we subdivide each of the four modules into several small modules, as shown in Figure 2.

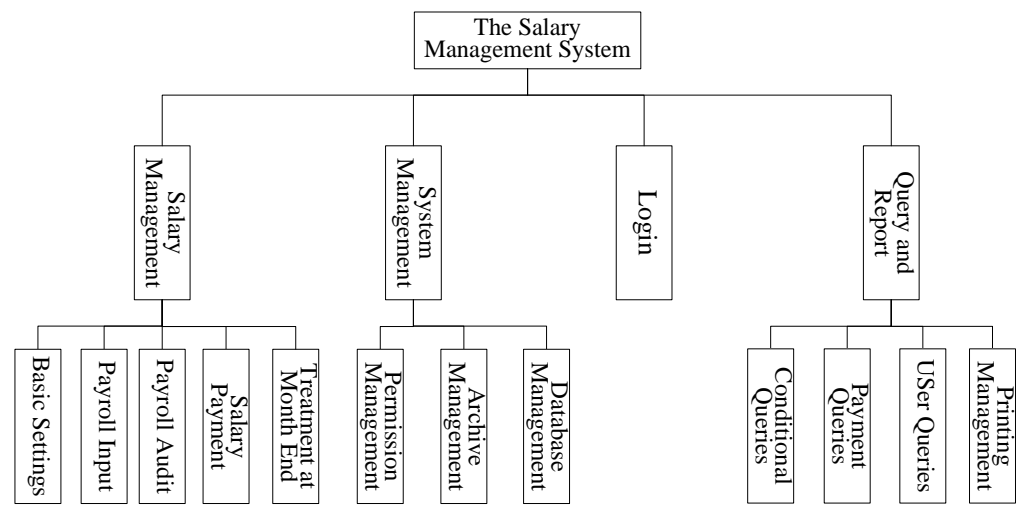

Figure 2. Functional modules

\subsection{Database Design}

In this paper, we adopt the entity-relationship (ER) model based relational database, which shows many advantages, such as high structured data, minimum redundancy, independence of procedures from data and easy expandability. The ER model provides methods of entity types, properties and relationships to describe the real world based on the conceptual model, which is the initial stage of the database design.

According to the requirement analysis, we design an ER diagram, as shown in Figure 3 , by using Powerdesigner 15, which is one kind of database tools. It can be seen from 
this figure that there are three entities, which are the user information table SMS4HVC_USER, the faculty information table SMS4HVC_STAFF and the wage information table SMS4HVC_WAGE.

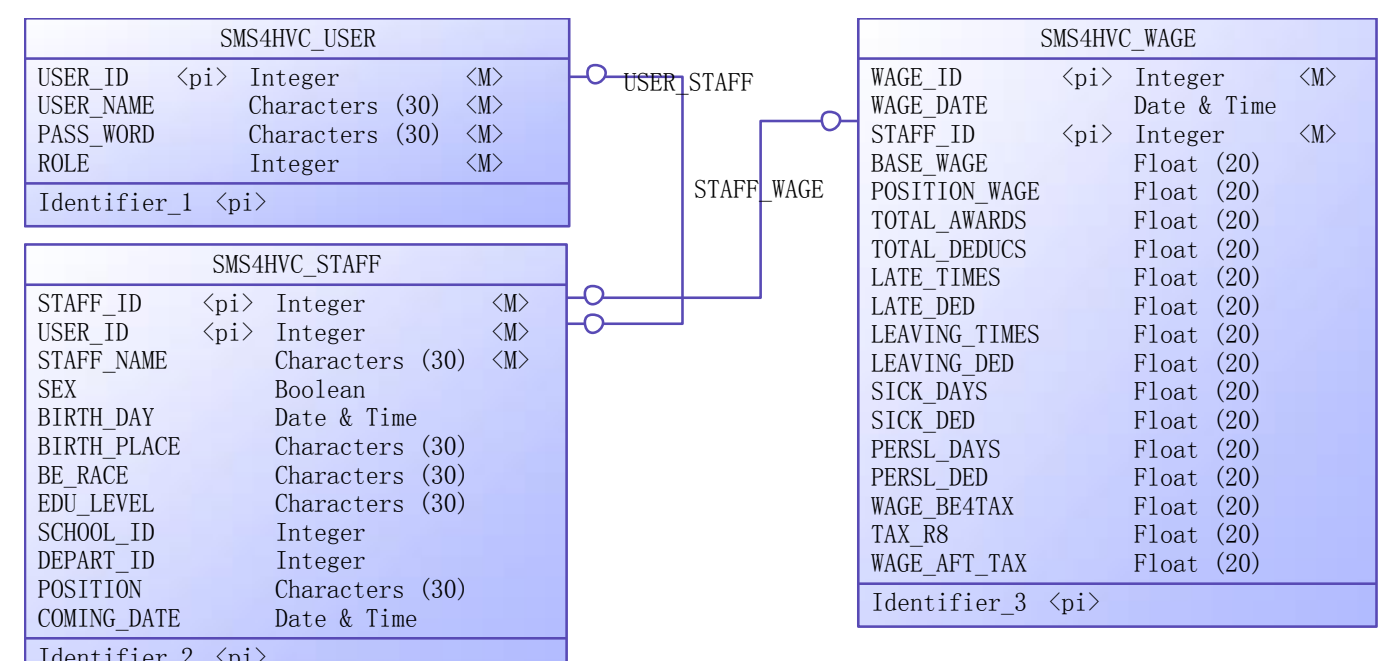

Figure 3. Entity-relationship (ER) Model

\subsection{Business Process}

The business process design is adopted to determine relationships among basic elements and other elements of the business process, such as participants, business targets and business strategies. The purpose of the business process design is to generate a more reasonable new business process by analyzing detailed requirements from business aspect and technology aspect. The transaction flow diagram (TFD), as a result of the business process design, is a water book for denoting specific business processes by specified symbols and line and representing business relationships among different entities. In order to develop a practical salary management system, we investigate several higher vocational colleges in Guangzhou city for their business processes. Besides, we conclude the investigation results in a TFD, as shown in the Figure 4.

\subsection{Data Process Design}

The data process design is used to abstract non-physical components, such as the data flow, the data transformation, and the data storage, from the desired system in the data flow aspect. The purpose of the data process design is to discover and solve issues in the data flow, such as unsmoothed flows, unmatched data and unreasonable data process. As a result of the data process design, the Data Flow Diagram (DFD) is a main tool for describing the system logical model, and a graphic representation method for the structural system design, by several specified symbols.

Basic components of the DFD are external entities, processing procedures, the data storage and the data flow. Multitier architecture is applied to analyze the complex data flows: (1) The top tier. This tier determines boundaries, i.e. inputs and outputs, of the system. (2) The middle tier. This tier is a decomposition result of its upper tier and an abstract of its lower tier. (3) The bottom tier, which consists of indecomposable data flow. For convenience, we illustrate how we design the first two tiers in this paper. Firstly, the top tier of the DFD is shown in Figure 5. 


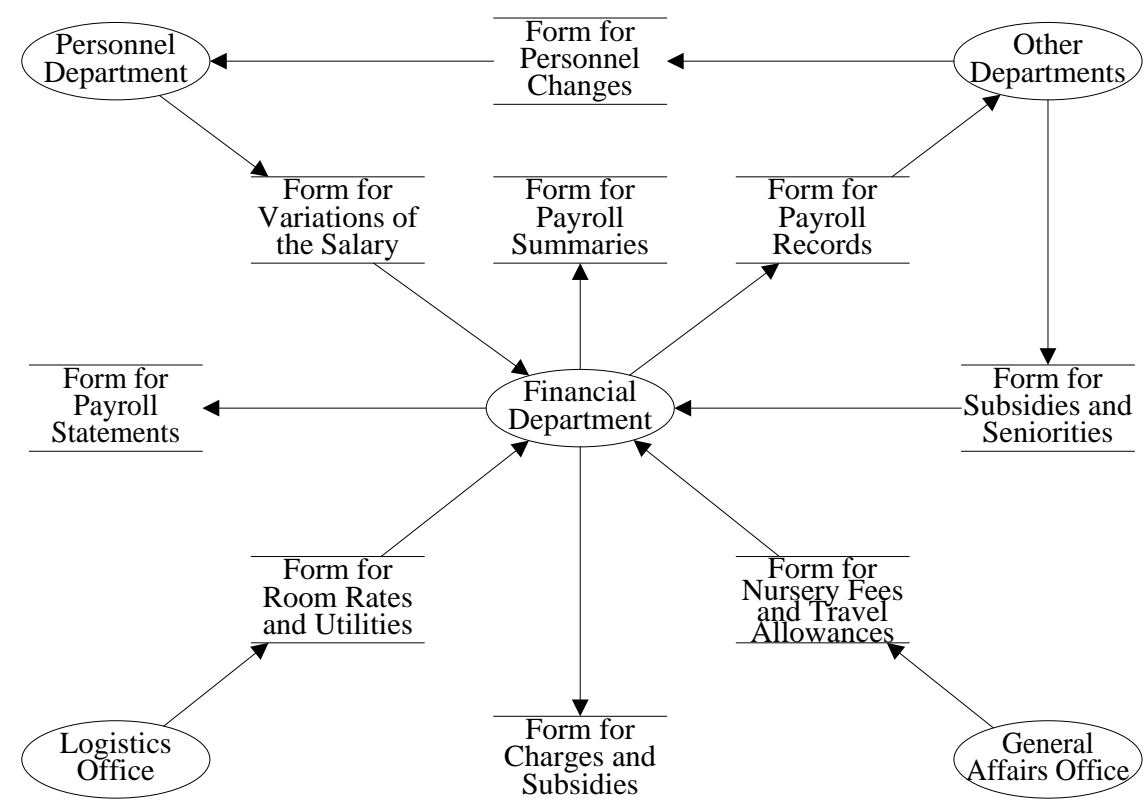

Figure 4. Transaction Flow Diagram for Salary Management of Higher Vocational Colleges

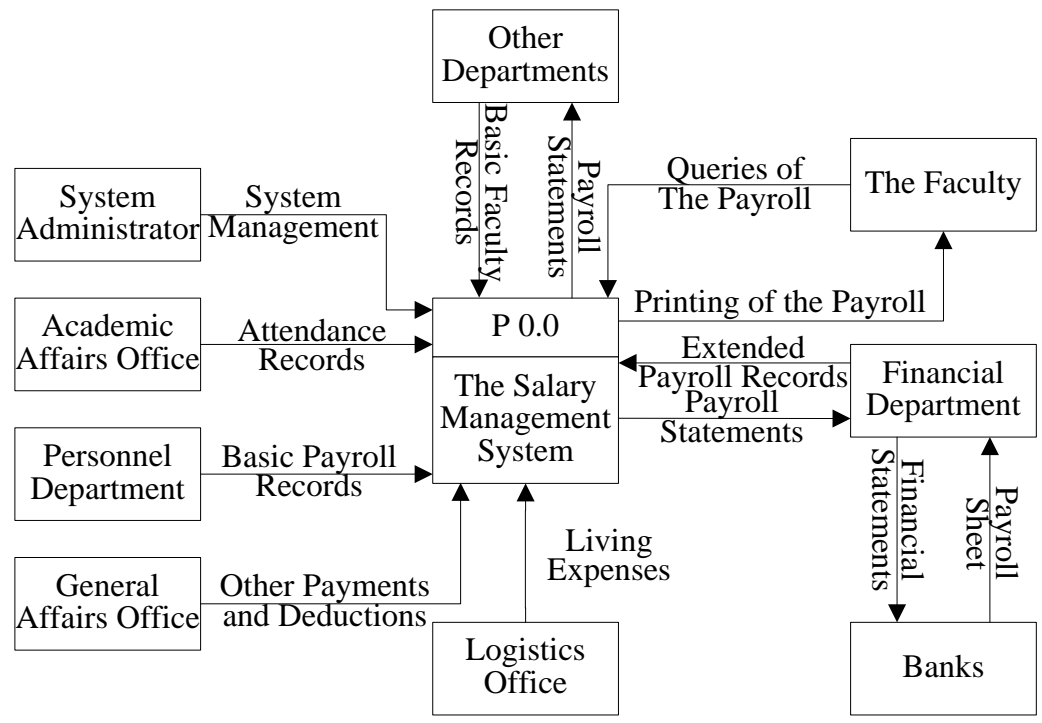

Figure 5. Top Tier of the Data Flow Diagram

Then, the second tier of the DFD can be obtained by refining on the top tier, as shown in Figure 6, where F1 is the form for room rates and utilities, F2 is the form for ratings of the faculty, F3 is the form for personnel changes, F4 is the form for living expenses, F5 is the form for nursery fees and travel allowances, F6 is the form for other detailed payments and deductions, F7 is the form for personal information, F8 is the form for payroll records, F9 is the form for basic information of the faculty and F10 is the form for payroll statements. 


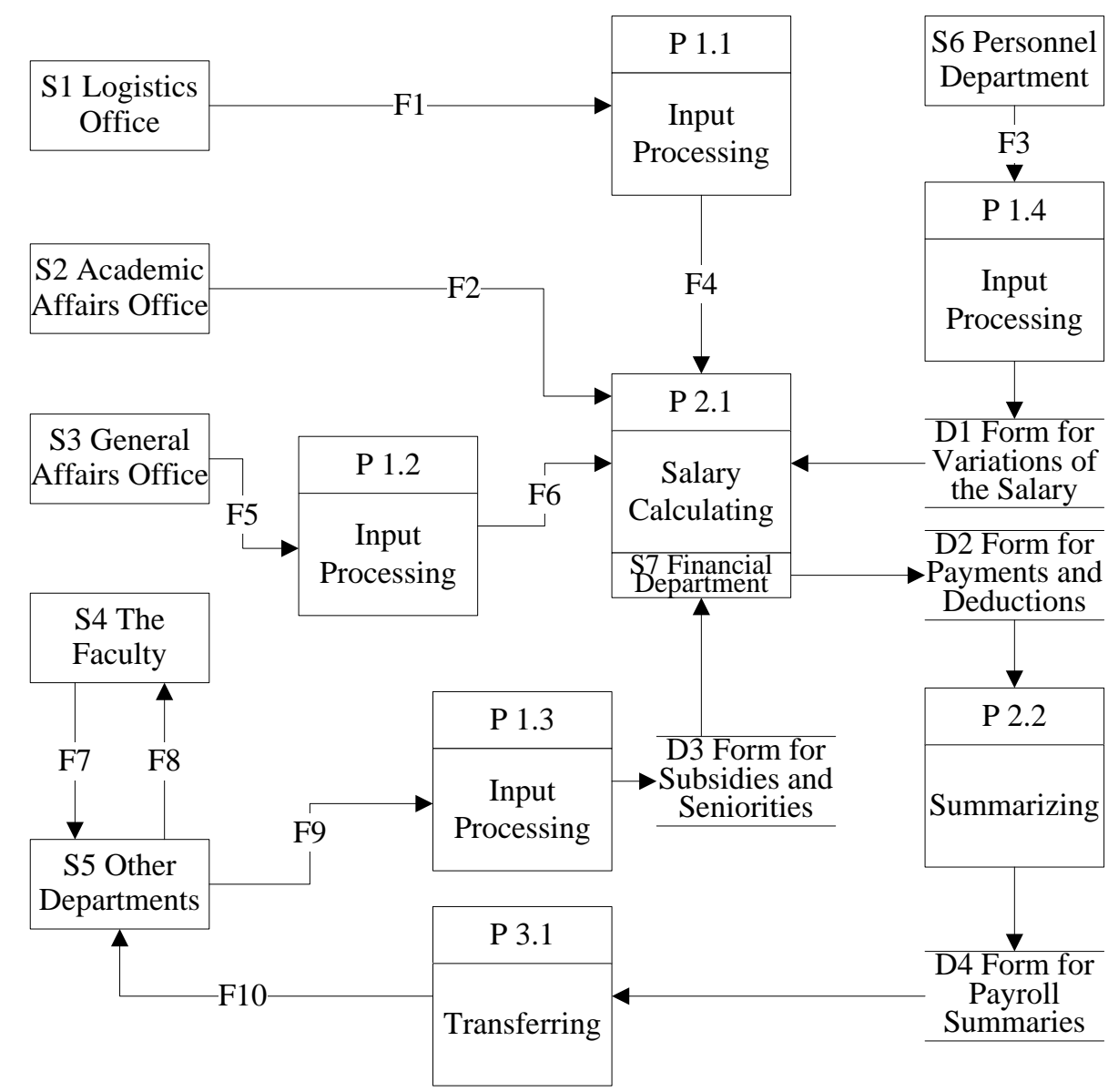

Figure 6. Second Tier of the Data Flow Diagram

\subsection{Use Case Design}

A use case diagram is a dynamic representation of system functions, which involves the actor, the use case, and the relationship between the actor and the use case. From the use case diagram, we can understand external functions of the system without implementation details based on actors, use cases and their relationships. The actor, which could play roles of a person, a thing, or a system, is an entity outside the system and participates in the process of several user cases.

There are three roles for the salary management system, which are the system administrator, the financial department, and the faculty. In order to describe intuitively functional requirements, Figure 7 shows three use case diagrams, with each for one role.

\section{System Implementation}

\subsection{Implementation Environment}

To implement the salary management system, we should configure two kinds of environments, which are the runtime environment and the development environment. 


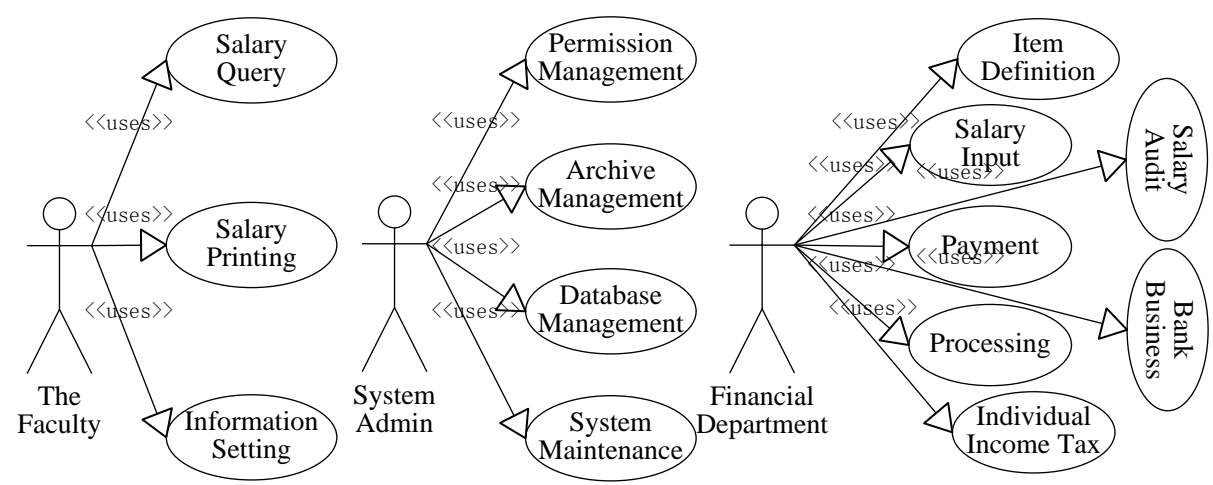

\section{Figure 7. Use Case Diagrams for the Faculty, System Administrator and Financial department}

We adopt the Microsoft SQL Server 2005 [2] as the relational database management system (DBMS), which together with Oracle and Sybase are the most popular DBMS. For convenient database modeling and design, we use the PowerDesigner 15 software [4], which is a very good database designer tool for data flow diagram, conceptual data model, and physical data model. For the web server, we take the IIS 6 (Internet Information Services) [6], which is a Windows based web component by the Microsoft. Although many versions of Microsoft Windows have already contained IIS, the IIS service is not started by default. Take the Windows 7 operating system as an example, we explain how to start such a service through steps of: (1) Click successively: control panel-> programs$>$ programs and features->turn windows features on or off. (2) In the opened windows features dialog, check successively three sub-items of the Internet information service, which are the IIS management console, the IIS management scripts and tools, and the IIS management service. For the integrated development environment of the ASP.NET, we consider the Microsoft Visual Studio 2005 (VS 2005), which is a perfect development toolkit for desktop applications, web applications, web services, applications for intelligent devices, and office plug-ins.

\subsection{The Salary Management Module}

We implement the salary management module from five aspects, which are basic settings, payroll input, payroll audit, payment of salaries, and treatment at the end of a month. Specifically, we achieve the function of the basic settings from four aspects, which are parameter setting for the income tax formula, item setting for floating wages, item setting for gross wages, and item setting for deductable wages, as shown in Figure 8.

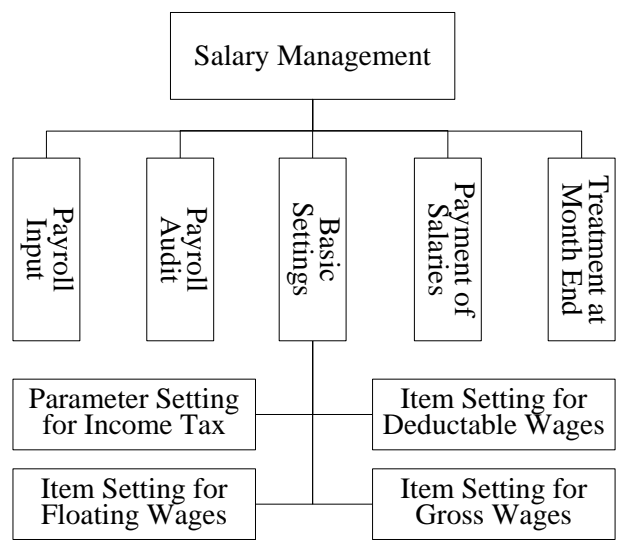

Figure 8. Implemented Functions for the Salary Management Module 
Accordingly, we show the web page for the salary management module in Figure 9, where we could set many parameters, change many items, and consider only basic wages as well as position wages for gross wages.

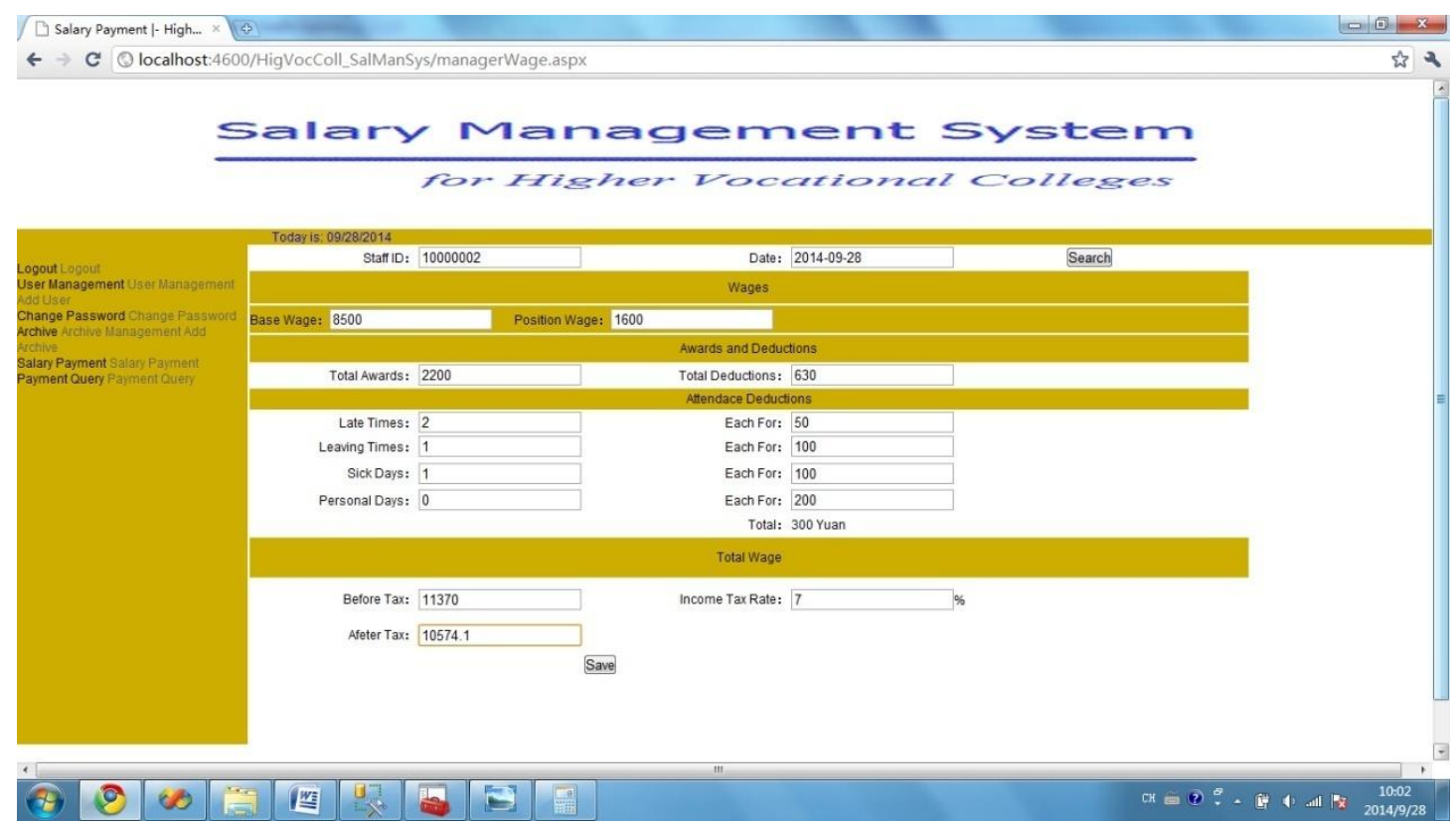

Figure 9. The Web Page for the Salary Management module

\subsection{The System Management Module}

From the requirement analysis, we can observe that the system management module involves three major functions, which are the permission management, the archive management and the database management. In this section, we implement each of these functions by several sub-modules. Specifically, we firstly consider the role management, the permission assignment and the permission adjustment for the permission management. Then, we take into account the user addition, the user deletion and the user modification for the archive management. Last, we implement the database management module from aspects of the database backup and the database restore. Figure 10 shows some details about the sub-modules we implement for the system management module.

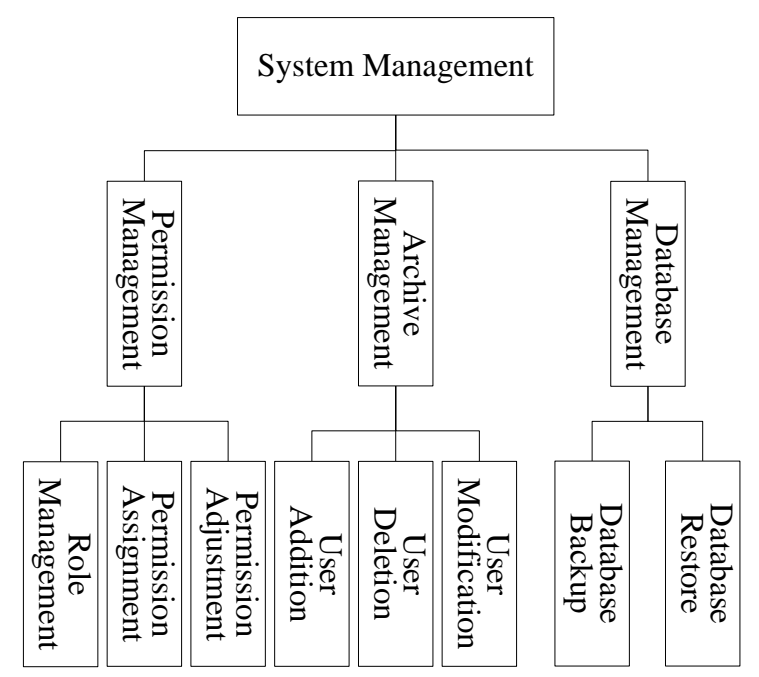

Figure 10. Implemented Functions for the System Management Module 
Next, we show the web page for the system management module in Figure 11, where we could achieve four basic database operations, which are create, read, update and delete (CRUD), for all system roles.

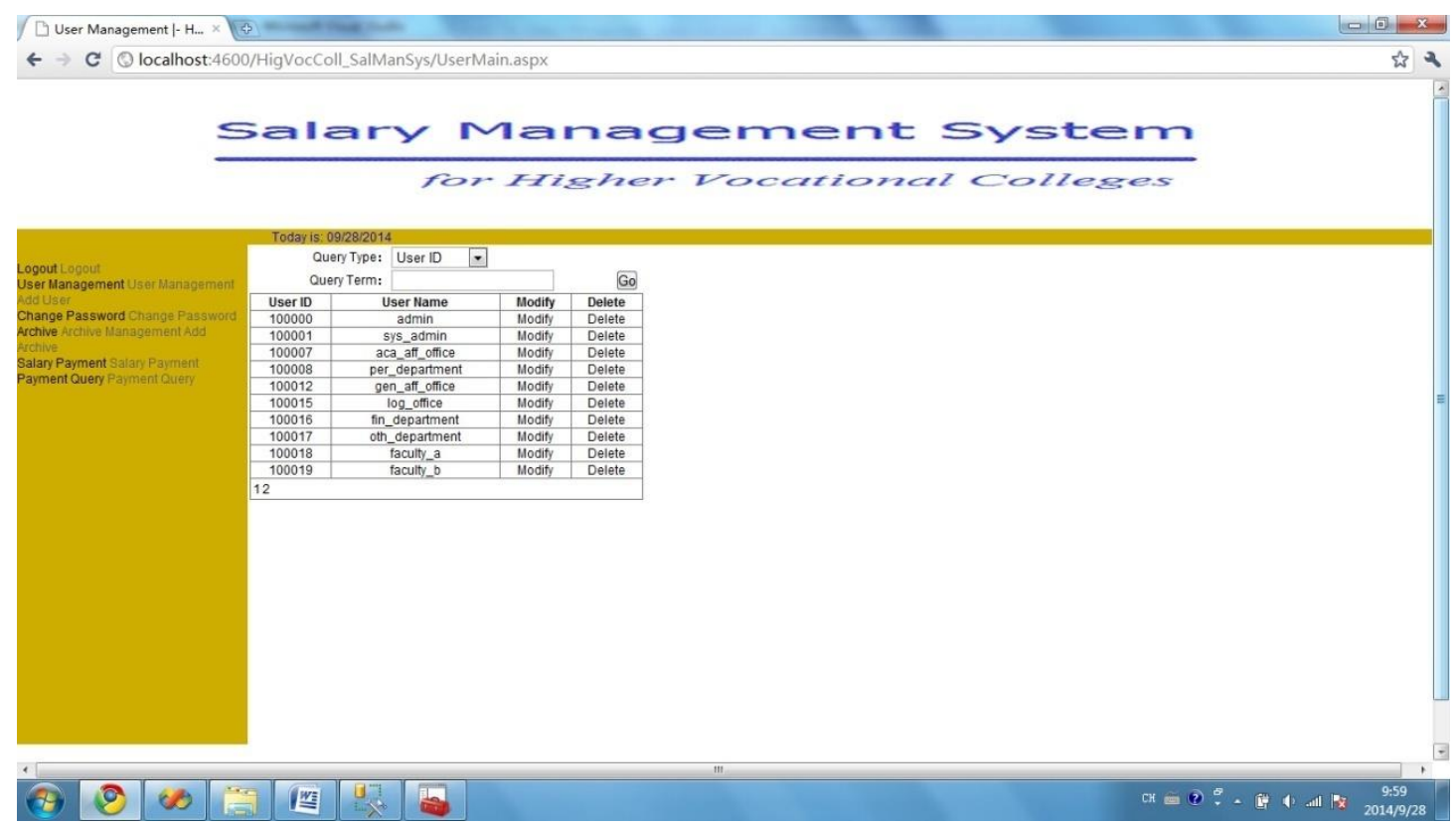

Figure 11. The Web Page for the System Management Module

\subsection{The Login Module}

Users could enter their web pages through the login module in the main web page of the salary management system. As described in the use case design section, there are three roles for the salary management system, which are the system administrator, the financial department, and the faculty. The main function of the login module is to identify the role of the possible user by the input information and assign accordingly their web pages. Figure 12 shows the flowchart of the login module.

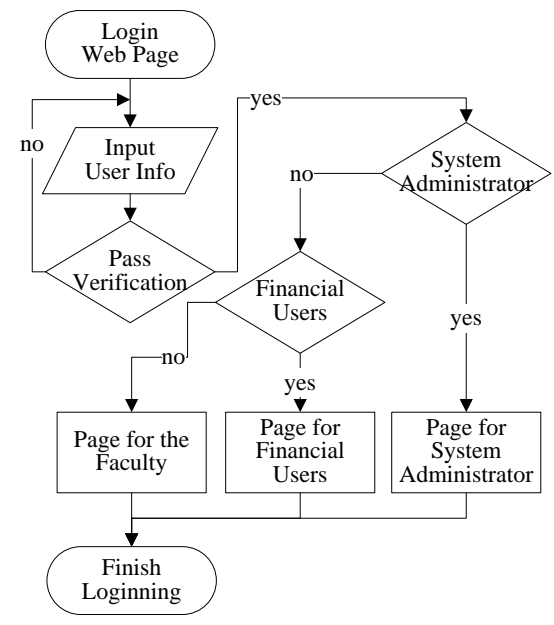

Figure 12.The Flowchart of the Login Module

Figure 13 shows the web page for the login module, where the user name, the password and the verification code are required to identify further the role and the main web page of the current user. 


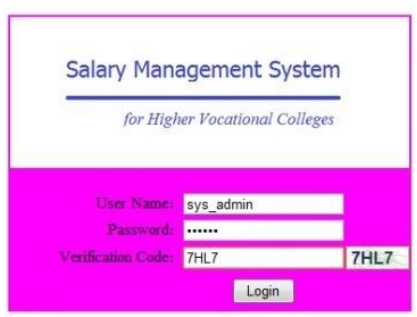

\section{Figure 13.The Web Page for the Login Module}

\subsection{The Query and Report Module}

For the query and report module, we implement four functions, which are queries of payment records, queries under configurable conditions, queries of users and printing managements, as denoted in the requirement analysis section. Furthermore, we firstly realize the queries of payment records by queries of payroll records, queries of changeable payment items and queries of aggregate payment records. Then, we realize the printing managements by the setting of printer, the printing of payroll records, and the printing of user information. Figure 14 shows which functions we implement for the query and report module.

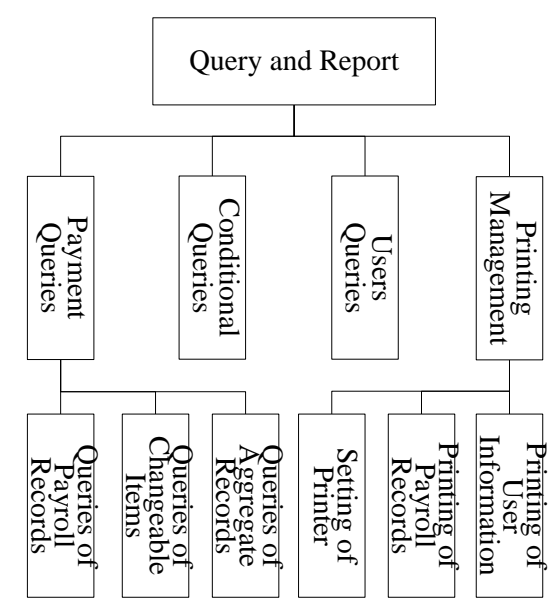

Figure 14. Implemented Functions for the Query and Report Module

Figure 15 shows the web page for the query and report module. It can be seen that system users could query and report accordingly records through many combinations, such as the payroll date, the faculty name, and the faculty identifier. 


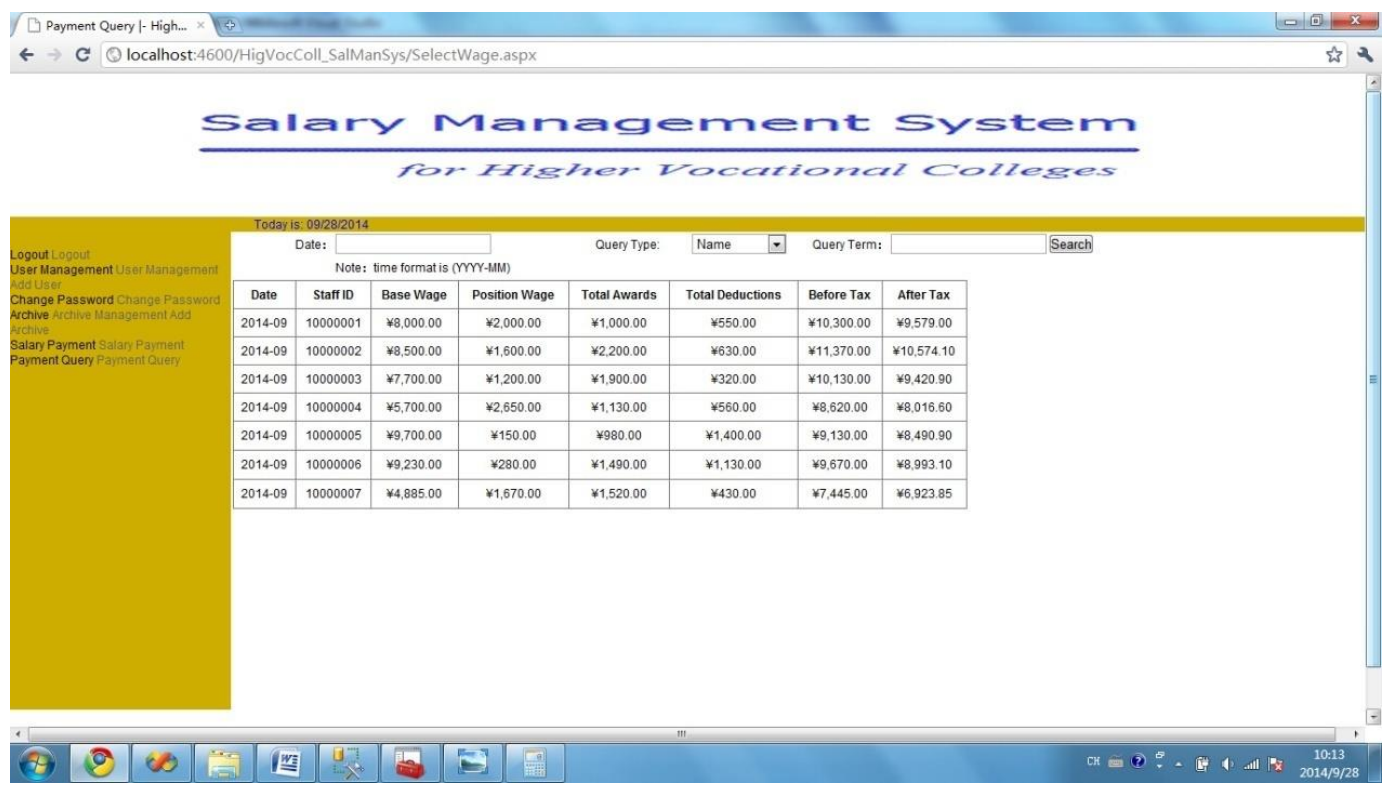

Figure 15. The Web Page for the Query and Report Module

\section{Conclusion}

In this paper, we developed a three-tier salary management system for higher vocational colleges, which aims at providing financial staffs as well as the faculty of all departments with efficient salary management services, and the personnel department with salary related convenient sharing data. However, the salary management of higher vocational colleges is a complex social issue, which can't be solved from only the technical aspect. The challenging employment circumstances require us to make accordingly major adjustments to our thinking as we offer guidance on the salary management for higher vocational colleges through developing new information systems. We achieved our predetermined target by the developed system. In the future, we want to substitute the nHibernate based framework for the current used DAO framework in order for more complex salary management related businesses, and add more data tables to the database, where there are only three data tables used in this paper.

\section{Acknowledgments}

This paper was supported by the Doctor Startup Foundation of Wuyi University under Grant No. 2014BS07, the Basic Theory and Scientific Research Project of Jiangmen City under title "Research on complex network evolution model and link prediction", and the National Natural Science Foundation of China under Grant No. 61402106. We would like to thank anonymous reviewers for helpful comments.

\section{References}

[1] I. Sommerville and G. Kotonya, "Requirements engineering: processes and techniques," John Wiley \& Sons, Inc., (1998).

[2] Wikipedia, "Microsoft SQL server" [EB/OL]. [2014-06]. http://en.wikipedia.org/wiki /Microsoft_SQL_Server.

[3] H. Wang, "Study on behavior simulation for picking manipulator in virtual environment based on binocular stereo vision," In ICSC, (2008), pp. 27-31.

[4] Wikipedia, "PowerDesigner" [EB/OL]. [2014-06]. http://en.wikipedia.org/wiki/PowerDesigner.

[5] B. Lu, "Discovery of community structure in complex networks based on resistance distance and center nodes," J. Comput. Inf. Syst., vol. 8, no. 23, (2012), pp. 9807-9814.

[6] Wikipedia, "Internet information services" [EB/OL]. [2014-06]. http://en.wikipedia.org/wiki /Internet_Information_Services. 
[7] C. Liu, "Modeling physical and chemical growths of avascular tumor," Int. J. Multimed. Ubiq. Eng., vol. 9, no. 4, (2014), pp. 349-362.

[8] S. Q. Hu, "Cloudy-based optimization of the human resource management system," In Adv. Mater. Res., vol. 998, (2014), pp. 1557-1562.

[9] $\mathrm{H}$. Li, "A modified biphasic system for the dehydration of D-xylose into furfural using $\mathrm{SO}_{4}{ }^{2-} / \mathrm{TiO}^{2-}$ $\mathrm{ZrO}_{2} / \mathrm{La}^{3+}$ as a solid catalyst," Catalysis Today, vol. 234, (2014), pp. 251-256.

[10] Y. Xu, E. Kim, K. Lee, J. Ki, and B. Lee, "Using PhysX simulation fire model of backdraft in unity 3D game engine," Int. J. Multimed. Ubiq. Eng., vol. 9, no. 6, (2014), pp. 243-252.

[11] J. X. Chen, "Modeling and performance analyzing of helix transmission base on Modelica," Key Eng. Mater., vol. 455, (2011), pp. 511-515.

[12] Y. F. Dai and D. Shao, "Enterprise car service management system design based on MVC framework," In Appl. Mech. Mater., vol. 529, (2014), pp. 735-738.

[13] H. J. Wang, "Study on a location method for bio-objects in virtual environment based on neural network and fuzzy reasoning," In ICIRA, vol. 5928, (2009), pp. 1004-1012.

[14] X. Yang and S. Liu, "Dynamic adjustment strategies of inertia weight in particle swarm optimization algorithm," Int. J. Contr. Autom., vol. 7, no. 5, (2014), pp. 353-364.

[15] Y. Kim and H. Chang, "The industrial security management model for SMBs in smart work," J. Intell. Manuf., vol. 25, no. 2, (2014), pp. 319-327.

[16] C. Liu, "Research on service-oriented and HLA-based simulation model of juice production line," In ICMTMA, vol. 3, (2010), pp. 167-170.

[17] H. Noori, A. Nikdel, and M. Mosleh, "Energy efficient topology control protocol for wireless sensor networks," Int. J. Smart Home, vol. 8, no. 3, (2014), pp. 61-74.

[18] H. Li, "Catalytic hydrothermal pretreatment of corncob into xylose and furfural via solid acid catalyst," Bioresource Technol., vol. 158, (2014), pp. 313-320.

[19] Z. Fu, "Research on model of distance education system based on SIP protocol," Int. J. Multimed. Ubiq. Eng., vol. 9, no. 5, (2014), pp. 63-72.

[20] H. J. Wang, "Structure design and multi-domain modeling for a picking banana manipulator," $A d v$. Mater. Res., vol. 97-101, (2010), pp. 3560-3564.

[21] Y. H. Al-Mamary, A. Shamsuddin, and A. N. Aziati, "Key factors enhancing acceptance of management information systems in Yemeni companies," J. Bus. Manag. Res., vol. 5, (2014), pp. 108-111.

[22] C. Y. Yang, "Design and implementation of university administrative management system," In Appl. Mech. Mater., vol. 599, (2014), pp. 2104-2107.

\section{Authors}

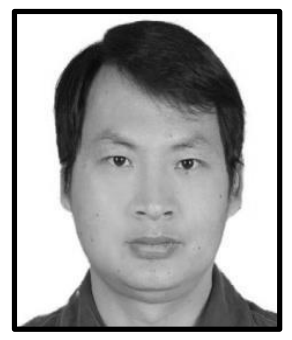

Bin Lu, he is currently a lecturer in the School of Computer Science at Wuyi University. He received his Ph.D. degree in 2013 from South China University of Technology. He is a reviewer of the Journal of Yangtze River Scientific Research Institute since 2010. His main research interests include complex network and machine learning.

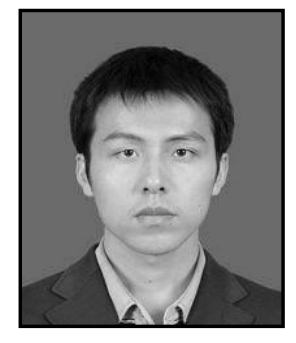

Changyu Liu, he joined the Communication and Computer Network Lab of Guangdong as a PhD student in 2010 at South China University of Technology, advised by Prof. Shoubin Dong. He was a Visiting Scholar at the School of Computer Science, Carnegie Mellon University, from September 2012 to October 2013, advised by Dr. Alex Hauptmann. Then, he worked with Prof. Mohamed Abdel-Mottaleb at the Department of Electrical and Computer Engineering, University of Miami, from October 2013 to September 2014. His research interests include computer vision and machine learning. 


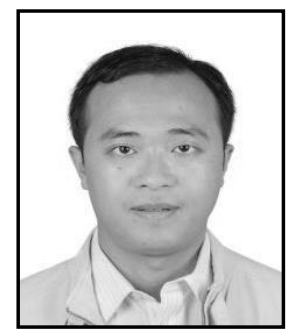

Tiezhu Zhao, he received the Ph.D. degree from South China University of Technology in 2011. He is currently a research associate at the Computer College, Dongguan University of Technology. His research interests include distributed/parallel computing, pattern recognition and network security. 
International Journal of Multimedia and Ubiquitous Engineering Vol.10, No.4 (2015) 